catalogers found the work "unrewarding and taxing" because of the inevitable inaccuracies in the cataloging and the rushing pressure. Of the cataloging entries printed $48 \%$ had some discrepancy with the book as published.

The Cataloging-in-Source experiment was begun in May 1958. Many publishers of varying sizes and types were contacted; 157 of them were willing and able to cooperate and sent in proof for cataloging. The goal was to catalog 1,000 titles, and by the end of February 1959, 1,203 publications had been cataloged by the Library of Congress, 100 of which were cataloged cooperatively by the Department of Agriculture Library. After the cataloging phase more than 200 libraries were visited by the consumer reaction team. Consumer reaction was sought from libraries of various sizes and degrees of specialization.

This report is very complete in including all of the procedures followed. This does not have to detract from the ease of reading it by those who wish to skim over these details. However, if anyone has difficulty in understanding the complications of the special cataloging routines involved for the Library of Congress, let him be sure to read pp. 5-7 where the basic routines are outlined. The make-up of the report involves first twentyfour pages of introductory remarks and acknowledgements-including a chronology of events. Then follows the main text for ninety-nine pages. Here the experiment is described step by step along with the Library of Congress' viewpoint, the publishers' experience and attitude, the report on the consumer reaction survey, the report of the ALA Cataloging Policy and Research Committee, as well as the final considerations and possible alternatives. The rest of the report is taken up with fourteen appendixes which include among others: samples from a similar experiment in the late nineteenth century, the forms, procedures, and other material sent to the publishers, the report on Cataloging-in-Source in the Department of Agriculture Library, the tables of statistics that were accumulated, the libraries that were visited during the Consumer Reaction Survey and the questionnaire used, and even a bibliography entitled "A Chronological Description of the More Important Published Accounts of the Experiment."

The library world is grateful to the Coun- cil on Library Resources, Inc. for the grants which made this experiment possible, to the publishers who cooperated in it, and to the Library of Congress for carrying it out. This fine report records in one convenient place all that has been involved in the experiment, the results, the conclusions drawn, and the possible future alternatives. Librarians everywhere will certainly want to read it.-Kenneth W. Soderland, University of Chicago Library.

\section{Studies in Microforms}

Production of Micro-Forms. By Reginald Hawkins. (The State of the Library Art, edited by Ralph R. Shaw, Vol. 5, Pt. 1.) New Brunswick, N. J.: Rutgers University Press, 1960. 208p. $\$ 5.00$.

Reading Devices for Micro-Images. By Jean Stewart and others. (The State of the Library Art, edited by Ralph R. Shaw, Vol. 5 , Pt. 2.) New Brunswick, N. J.: Rutgers University Press, 1960.205 p. $\$ 5.00$.

These two volumes are the first to appear out of the Rutgers project on "Targets for Research in Library Work" sponsored by a grant from the Council on Library Resources, and directed by Ralph R. Shaw. Part three on the "Production of Full-Size Copies," due shortly, will complete the portion devoted to "Reproduction of Materials." The purpose of these volumes is to show what has been done in the past, evaluate those previous studies, and point out directions for future work.

The arrangement of materials is somewhat different in each book. Hawkins starts out with the review of what has been written on the production of microforms. This covers the history of microcopying, equipment in general, types and characteristics of microcopies, quality factors, production costs, and storage. This 149-page review is based on a list of some 439 references. It is followed by a thirteen page summary and suggestions for future study. Hawkins lays out five research projects ranging from a study to determine which types of microforms are necessary to one on information retrieval based on microforms. 
In Miss Stewart's book, the summary and evaluation come at the beginning, and the review is broken into two parts. The first part, which is chronologically arranged, takes up ninety-four pages and is based on some 284 references. The second part, a topical summary, takes sixty-seven pages to list some forty-two features by which the reading machines are classified. These range from cost of the equipment, through the various optical and mechanical features, to end with use costs.

The chief value of these two volumes lies in their chapters of recommendations and their bibliographies. The former will be fertile fields for doctoral candidates looking for subjects for dissertations. They will also be used by industry to help lay out research projects on present and future equipment. The two bibliographies bring together just about all that one could find in this field up to 1957 . I suspect that many students will be shuffling these lists into manifold arrangements for some time to come.

The outstanding shortcoming of both books lies in the lack of illustrations. The descriptions of equipment and techniques cry for pictures and diagrams. The evaluation of equipment and processes in both books is somewhat undescriminating. There is little weight given as to who made what judgment when. There are surprisingly few errors when one considers what a wide range of time and subject matter is covered. One that will amuse those who know him is the appearance of Frank and Frederic Luther, both writing about Dagron.

Library Trends, VIII (1960), no. 1 (Photoduplication in Libraries. Edited by James E. Skipper.)

Photoduplication has been the subject of single articles appearing in four previous issues of Library Trends. Now it has an issue of its own. Of the ten papers presented here, seven are on the administrative aspects and three on the technological phases of the field. Of an administrative nature are: Lester $\mathrm{K}$. Born, "History of Microform Activity"; Lawrence S. Thompson, "Microforms as Library Resources"; John A. Riggs, "The State of Microtext Publications"; George A. Schwegmann, Jr., "The Bibliographical Control of Microforms"; H. Gordon Bechanan, "The
Organization of Microforms in the Library"; Robert E. Kingery, "Copying Methods as Applied to Library Operations"; Miles O. Price, "Photocopying by Libraries and Copyright: A Precis."

Of greater interest to the technologists in the field are: Robert H. Muller, "Policy Questions Relating to Library Photoduplication Laboratories"; Charles G. La Hood, Jr., "Microfilm as Used in Reproduction and Transmission Systems"; Peter Scott, "Advances and Goals in Microphotography."

This issue is recommended reading for all who are interested in microfilming. Librarians responsible for organizing microform reading rooms will benefit by Bechanan's report on Harvard's progress in this line. Heads of library photoduplication laboratories will be thankful to Muller for his survey of their problems. Commercial microphotographic agencies about to embark on projects aimed at libraries would do well to study the articles by Thompson, Riggs, and Schwegmann. This issue will be on library school reading lists for some time to come.

Microtexts as Media for Publication: The Papers and Discussion of a Symposium Held at Hatfield Technical College on the 10th November 1959 . . Hatfield, Herts., England: Hertfordshire County Council, 1960. 87p. 9 s.

Hatfield is located twenty miles north of London (about as far from its center as Scarsdale is from Times Square) and is the source of an increasing number of important publications on photoduplication. In January 1958 a Symposium on Microtexts and Microrecording was held, and its papers published. A Symposium on Modern Copying Techniques followed in January 1959, resulting in another booklet. The third publication is perhaps of greatest interest to librarians. It consists of papers presented on microfilm, microfiche, and Microcard, and considers them from the standpoint of their suitability for publication of scholarly material.

The first paper is on "Microfilm-The Versatile Academic Tool" by Eugene Power of University Microfilms. It contains a wealth of information baséd on twenty-five years of experience with this medium. This is followed by Dr. L. J. van der Wolk's report on "Publishing on Microfiche." This presents a 